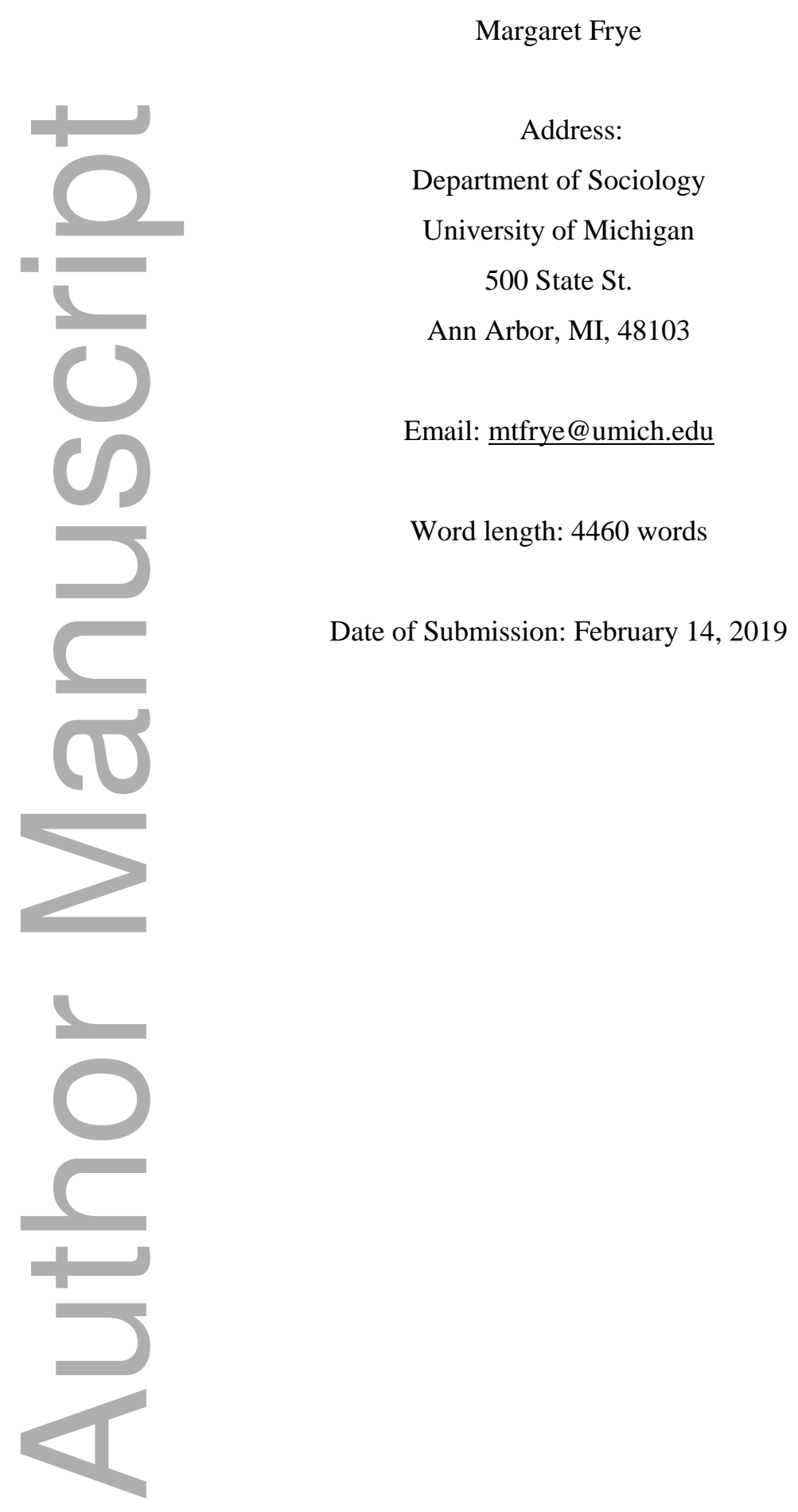

This is the author manuscript accepted for publication and has undergone full peer review but has not been through the copyediting, typesetting, pagination and proofreading process, which may lead to differences between this version and the Version of Record. Please cite this article as doi: $\underline{10.1111 / 1468-4446.12662}$

This article is protected by copyright. All rights reserved 
DR. MARGARET FRYE (Orcid ID : 0000-0002-3534-5733)

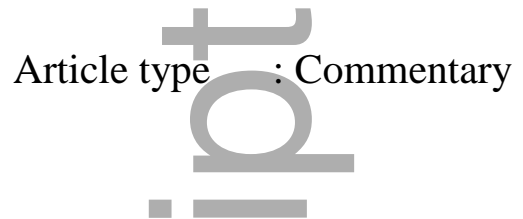

The Myth of Agency and the Misattribution of Blame in Collective Imaginaries of the Future

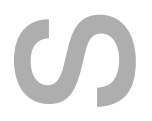

In her essay entitled "From Having to Being: Self-Worth and the Current Crisis of American Society," Michèle Lamont presents a galvanizing discussion of possible ways that cultural sociologists might use our expertise to address the existential angst and widespread despair that seem to permeate American society today. The crux of her argument is that the American Dream is ineffective as a collective narrative, primarily because it focuses on a single criterion of success - material prosperity_which "dominates all other dimensions of human achievement." We cannot all rise into the middle class, and in fact fewer of today's young adults can do so than in previous generations, and thus Lamont laments that we are "dreaming an impossible dream" (Lamont 2019, p. 8). In response, she proposes that we should promote a broader set of cultural models of success, such that people will aspire to achieve not only material wealth (having) but also social connections and moral convictions (being).

As I read this essay, I found myself nodding in affirmation with Lamont's diagnosis of the psychological costs of the widespread failure of the American Dream, and I heartily agree that these problems are not only the result of structural barriers and material inequities but also stem from cultural processes. Yet, as a scholar who has examined the cultural correlates of education and the theoretical question of how shared ideals and future aspirations impact people's lives in the present, I would like to propose here a slight modification of Lamont's call to action. Youth today may be dreaming an impossible dream, but the element of the American Dream that is in my view most harmful to our collective wellbeing is not its optimistic (and to some degree unattainable) imagined destination, but rather its unrealistic account of the means 
through which people can arrive there. Rather than working to promote a different set of aims, as Lamont suggests here, it may be more helpful to focus on a cultural reframing of the causal pathways connecting individuals' present circumstances with later life outcomes, one that more directly recognizes the role played by institutional weakness, social discrimination, and the reproduction of inequality. Dominant cultural narratives locate these causal pathways in the actions or inactions of the individual aspirants, leaving the extra-individual forces that keep people from achieving their future goals to escape our collective gaze.

I illustrate these points by drawing upon my research on young adults' educational and career aspirations in Malawi and Uganda. My starting off point is thus where Lamont ends her essay — what she in her final sentence describes as "a whole new set of questions that are better left for another day" (2019, p. 43) — how cultural narratives of future success circulate in other international contexts. Looking beyond the local historical and political dynamics that undergird the American Dream, I show how collective myths about the future shape subjective experiences of unmet ambition in places where dashed hopes are even more rampant than they are in the contemporary United States. Drawing insights from the research that I have conducted over the past decade about the cultural myths surrounding educational expansion in sub-Saharan Africa, my goal is to add an international comparative perspective that will not only reveal some interesting contrasts between the American and African contexts, but also provide some more general clarifications and insights about the subject at hand: the role played by cultural myths in shaping the subjective experience of dashed hopes and stagnant economic trajectories. In other words, I hope to bring to this dialogue a bit of the comparative cultural sociology that Lamont has long championed (see, for example, Lamont and Thevanot 2000; Lamont 2012).

\section{The American Dream and the Misattribution of Blame}

As Lamont describes in her essay, the American Dream has four primary tenets: "1) equality of opportunity, so that the dream is perceived as accessible to all, 2) the hope of success, 3) the view that success results from actions and traits under one's control, and 4) the belief that success is associated with virtue." As this definition aptly conveys, what makes the American Dream cohere as a collective myth is not its account of what American youth aspire to, but rather its account of how a person achieves success: the architecture connecting present circumstances 
to an imagined future. According to the American Dream, it is a person's own effort and achievement - rather than where they come from, who they are, or the environment in which they are currently embedded - that largely determines whether or not they will succeed.

Lamont advocates new "narratives of hope" that broaden the criteria of success beyond material resources and valorize types of success that are not resource dependent. The first two elements of these alternative narratives center on changing what success looks like, or how we define a life well lived. First, she envisions that we should work to "valoriz[e] social contributions that are not directly tied to production and consumption, such as caring, educating, consecrating, and other types of activities, without subordinating them or justifying them by profit maximization" (p. 32) And second, she advocates that we promote "ordinary universalism" or "valorize... what people believe all people have in common" (p. 30) ${ }^{1}$ Her third proposal, in contrast, focuses on our collective understandings of what causes success or failure: "removing blame in order to refute the notion that a specific group deserves their lot because of their behavior" (p. 31). This final recommendation comes closest to what I'm advocating for in this response.

I share Michele's conviction that we need to not only address structural inequities but also seek to shift our collective narratives about the future. Nonetheless, rather than changing our shared definition of a good life and promoting a more inclusive vision of what is valued, sociologists are best positioned to promote a more realistic understanding of how divergent trajectories happen: how some succeed and others fail to achieve shared visions of success. More specifically, we should work to increase social recognition of extra-individual constraintsinstitutional weaknesses, systemic discrimination and deep-rooted inequality of opportunityinto our shared understandings of what drives success in America. This will help to both contextualize experiences of failing to achieve one's goals and potentially facilitate collective action aimed at reducing these structural barriers.

This focus on destabilizing the false sense of self-propulsion underlying the American Dream and other dominant aspirational myths is also more consistent with what sociologists of culture can do best. The tools of cultural sociology ready us to shed light on moments when our cultural understandings are particularly at odds with objective reality (Frye 2017; Collins 2019;

\footnotetext{
${ }^{1}$ The repeated use of the verb "valorize" here reveals the extent to which these components rest on changing our shared criteria of what a successful future looks like, rather than on how one does or does not achieve this future vision of success.
} 
Saguy 2012; Rosen 2017; Harding et al. 2017) and reveal how our shared cultural understandings shape our social relationships and life outcomes (Lamont et al. 2015; Polletta et al. 2011; Bail 2015). These tools are less helpful for promoting alternative cultural content.

\section{Secondary Students in Malawi: Irrational Agency Amidst Systemic Failure}

My first exposure to the empirical study of shared cultural narratives about the future took place in Malawi about a decade ago, in summer of 2008, when I asked a group of 40 female secondary students to describe what they imagined their adult lives would look like (Frye 2012). I encountered almost universal optimism: they imagined themselves attending university and securing jobs that many had never encountered in their own lives, including nurses, pilots, and engineers. In order to better understand the source of this surprising optimism, I compiled archival materials to analyze the ideological campaigns promoting formal education in Malawi surrounding the country's abolition of primary school fees about a decade prior. In these documents, including newspaper articles, school curricula, and magazines and posters targeting rural youth, I encountered a cultural model that bears a striking resemblance to the American Dream that Lamont describes in her essay. As in the United States, I identified four elements that are culturally construed to jointly produce future success in Malawi: "ambitious career goals, sustained effort, unflagging optimism, and resistance to (mostly sexual) temptations" (Frye 2012, p. 1565).

Similar to the American dream, this model promotes a causal sequence linking present circumstances with future outcomes that centers on the actions and inactions of the individual student. Work hard and be strong, the model promised, and you will succeed. Be lazy or allow yourself to be distracted along the way, and you will fail. This cultural model, in turn, led Malawian women to adopt a strikingly agentic perspective on their own futures, despite the fact that structural barriers and resource limitations permeated the educational system, such that fewer than one percent of students who begin primary school actually made it to university. This cultural model also led young women to interpret the experiences of those around them as signs of individual moral shortcomings rather than as indications of an inadequate opportunities and ineffective institutions. In other words, this model set Malawian youth up to interpret their almost inevitable inability to meet their ambitious aspirations as their own fault, in spite of widespread evidence to the contrary. 
This self-attribution of blame and perceived agency is not inevitable; instead it is institutionally configured. The popular perception that individuals control their own destinies is convenient for schools and governments, because it promotes individual investment in institutional pathways for self-improvement while protecting these same institutions from blame when these pathways do not lead to the imagined outcomes. This self-attribution is a key mechanism for the legitimation of inequality in contemporary society:

The achievement ideology ... maintains that individual merit and achievement are the fair and equitable sources of inequality of American society. If merit is the basis for the distribution of awards, then members of the lower classes attribute their subordinate position in the social order to personal deficiencies. In this way, inequality is legitimated (MacLeod 2009, p. 113, emphasis added).

In other words, this self-directed nature of our cultural myths both insulates institutions from blame for people's widespread failure to realize their dreams and reinforces the myth that destinies are determined by people's own effort and moral strength.

\section{University Graduates in Uganda: A Social Class Gradient of Self-Attribution}

Not only is this self-attribution not inevitable, it is also not universal. My more recent research, located in Kampala, Uganda, focuses on how university graduates navigate a context of widespread unemployment. This tendency to self-attribute failure to achieve aspirations is patterned by social class background, with disadvantaged youth being the most likely to internalize blame. The primary data for this ongoing data collection project consists of a set of longitudinal in-depth interviews with 60 men and women graduating from four universities across Kampala. I designed my sample to maximize variation in social class background, because I anticipated that as they left campus and began to look for work, students' trajectories would diverge along classed lines; youth from more advantaged backgrounds would be more likely to find jobs and land on their feet, while disadvantaged youth would be more likely to remain unemployed for extended periods, deriving little material benefit from their university educations. But even before these divergent trajectories could be observed, a notable difference was apparent in their imagined futures when I first spoke with these youth a year ago, during their final semester on campus. 
Across social class background, the destinations they envisioned were largely the same. Most respondents hoped to end up employed in offices or running successful businesses (or both), and they also wanted their careers to relate to their course of study and build upon the skills they developed while at campus. What differed along classed lines in these first-round interviews were the causal narratives linking their present circumstances with their imagined destinations. Among disadvantaged students, the primary narrative was one of institutionallysupported self-actualization. These youth believed in the power of their credential- they expected that excelling in their coursework and achieving a university degree would give them the tools needed to achieve success. What was needed, in their view, was their own sustained effort, leading them to graduate at the top of their class, find relevant positions and apply to as many jobs as possible. This meritocratic narrative is supported by the "education for all" messages that these youth had received since they were young, having come of age during the period when school fees were eliminated first for primary students and then for secondary students (Omoeva and Gale 2016; Mundy 2017). Having taken advantage of these new educational opportunities and progressed as far as they had, this narrative avows, they already had the tools necessary to achieve success. The disconnect between the number of students graduating and the number of jobs available was explained by a lack of effort. While most university graduates are lazy and take their achievements for granted, as newcomers into the university scene, disadvantaged youth are equipped with an keen sense of how special their positions are and are prepared to work hard to capitalize on the opportunities they have been given.

In contrast, respondents who come from a higher-class background express a causal narrative that emphasizes structural and institutional failures. Having come of age in a social environment in which most people around them attended university, they are acutely aware of how difficult it is to make the leap from degree to stable job. They have seen older siblings, family friends, and others around them fail due to the disorganization of the system. They tell stories about employers questioning the value of degrees due to rampant cheating and disfunction at universities. They describe observing people apply to hundreds of jobs, armed with a degree in a relevant field from a well-respected university, and not hear back from any of them. And most commonly, they speak of the extent to which the system of employment in Uganda is driven not by credentials and individual-level success but by social networks - it's not 
technical know-how but "technical know-who" that gets one a job in Uganda today (see also Reynolds Whyte et al. 2013). So, while they want the same futures that the disadvantaged youth envision, they express these futures as contingent on circumstances beyond their control.

These different causal narratives have important implications for the experience of dashed hopes. Interviews I conducted with older graduates, who have already been out of university for a few years, reveal a similar pair of narratives. Graduates from disadvantaged backgrounds believe that the strongest determinant of success is one's own effort, and they blame themselves for their nearly universal failure to secure stable employment. Graduates from more advantaged backgrounds, in contrast, believe that they system is rigged, and they are both less devastated by persistent unemployment and more likely to seek alternative means for gaining employment, most commonly relying on personal connections rather than educational credentials or the skills they developed in university.

In her recent book examining cross-national differences in women's understandings of work-family conflict, Caitlyn Collins (2019) demonstrates another example of cultural narratives that diverge primarily in terms of the extent to which outcomes are believed to be determined by the behavior or efforts of individuals alone or by extra-individual forces. Collins found that women's career interests chafed with their childrearing identities in all four countries in which she conducted interviews, though to differing degrees. Yet across national contexts, mothers referenced different causes of this conflict. While in the United States, women blamed themselves and their inability to achieve "work-life balance;" Italian mothers blamed the state; Swedish mothers blamed their country's unrealistic ideals for perfect equanimity between work and home life; and German mothers blamed outmoded cultural norms of motherhood (Collins 2019). Just as a middle-class membership is unattainable for everyone, complete harmony between work and family life is also likely an impossible ideal, as evidenced by the fact that Collins documents conflict in even the countries with the most progressive work-family policies. Yet by blaming mothers themselves for their widespread failure to achieve (or even come close) to this ideal, instead of attributing this failure to the state or our collective understandings of motherhood, American cultural narratives of motherhood contribute to women's isolation and dissatisfaction. And just as with our false myths of social mobility, cultural sociologists must work to reveal these harmful individualistic causal models and increase the social salience of the institutional and social mechanisms that shape mothers' outcomes. 


\section{Reframing the Dream: Destabilizing the Myth of Agency and Exposing Extra-Individual Forces}

Returning to the American dream and today's somewhat dystopian moment: Lamont is right, I believe, to characterize the American dream as overly materialistic. Would a wider set of popular images of success be helpful? No doubt. But material indicators of success are so deeply embedded in our capitalistic society that I fear that we have little hope of undermining their symbolic dominance. Neither are the materialistic preoccupations of contemporary American visions of success unusual, either from a temporal or geographic point of comparison. Eighty years ago, far before the neoliberal era, Merton (1938) was already decrying the fact that American society placed an exaggerated emphasis on the goal of monetary success. And a similarly materialistic focus of future aspirations can be found not only in sub-Saharan Africa, as I document in my research (Frye 2012), but also in other less developed contexts around the world (Lukose 2005; O’Dougherty 2002; de Koning 2009).

Empirical evidence on social class differences in future aspirations also contributes to my skepticism that the promotion of alternative indicators of success is an effective conduit for the destigmatization of poverty. Specifically, studies from multiple contexts have shown that purely material indieators of success - such as a vacation house, expensive vehicle, or nice clothes - are more salient to the future imaginaries of poor youth compared with more advantaged youth (Brown et al. 2009; Chaplin, Hill, and John 2014). Yet despite this emphasis on material achievement in their descriptions of their own future aspirations, there is also evidence that poor youth may hold a wider set of outcomes that they define as respectable - as indicators of "a life well lived." Drawing from his research on boys' imagined futures in an urban setting in the United States, David Harding (2010) describes how poor youth often aspire to attend university, but when asked to describe their role models, they describe people who did not achieve the indicators of success they just referenced in regard to their own futures, but instead overcame hardships and achieved moral clarity in the face of challenging circumstances-Harding (2010, p. 19) terms this the "turnaround narrative." These role models might be recovering addicts, fathers who have been in and out of prison, or youth who have involved themselves in gangs - a sharp contrast with the middle-class futures they themselves aspire to. In my own research in Uganda, I have found a similar pattern. When describing what they hope their future lives will 
look like, respondents mention owning a car, having a fancy phone, and wearing tailored clothes. But in the same interviews, they speak with deep respect, even reverence, about relatives and childhood who had none of those symbols - they may have never been to school, but persevered through hardship and provided a stable home.

Other research, examining the psychological effects of unrealized optimism, suggests that it is not the fact that most people's dreams are irrationally ambitious that is harmful for social integration and personal wellbeing. John Reynolds and Chardie Baird (2010) show that American high school students who stated they expected to complete university and later failed to graduate from high school are no more likely to be depressed than their peers who expected less and reached the same level. Conditional on educational attainment, they find no psychological consequences of unrealized ambition. Reaching for the stars and falling short does not lead to depression.

What makes the American Dream so destructive as a cultural myth is not that the destination - entry into the middle class and a more prosperous adulthood than their parents experienced - is distant and improbable for many who ascribe to this narrative. Instead, the problem is that in their imaginations, youth are responsible for not only driving the car but also for paving the road that leads to this destination; they are blamed for every barrier they encounter along the way. This myth of agency, I believe, is where we as cultural sociologists should focus most of our attention. The American Dream, along with other collective narratives that suggest that our success or failure hinge on our own actions, has the potential lead to despair, because it increases people's self-blame and encroaches upon their ability to work together against the external barriers keeping them from realizing their dreams. If one believes that they control their own destiny in a context in which their dreams are improbable, they are susceptible not only to disappointment but also to self-blame and the internalization of structural inequity.

By increasing our shared attention to the role played by social and institutional forces in shaping our divergent destinies, what I'm envisioning is a more pragmatic version of the American Dream, or the Education for All narrative, or any other optimistic vision of future success. Our collective imaginary about the future may still encourage everyone to reach high (whatever that means for them), but it must not pretend that some of us don't start off higher than others, with a shorter distance to go and a sturdier ladder to support us. By challenging the myth of self-propulsion at the center of our shared narratives about the future, we can ameliorate some 
of the personal shame that results from falling short of one's ambitions. We should conduct more research that reveals the inaccuracies of our causal narratives about the future and explores how these false narratives persist despite widespread evidence that they are wrong. As cultural sociologists, this is our most powerful method of supporting collective action-likely the only force that can ultimately work - geared toward reducing the structural inequities and social barriers that make ambitious dreams harder to realize for some groups than others.

\section{References}

Bail, Christopher A. 2015. "The Public Life of Secrets: Deception, Disclosure, and Discursive Framing in the Policy Process." Sociological Theory 33(2), pp. 97-124.

Brown, Ryan A., David H. Rehkopf, William E. Copeland, E. Jane Costello, and Carol M. Worthman. 2009. "Lifecourse priorities among Appalachian emerging adults: revisiting Wallace's organization of diversity." Ethos 37(2), pp. 225-242.

Chaplin, Lan Nguyen, Ronald Paul Hill, and Deborah Roedder John. 2014. "Poverty and materialism: A look at impoverished versus affluent children." Journal of Public Policy \& Marketing 33(1), pp. 78-92.

Collins, Caitlyn, 2019. Making Motherhood Work: How Women Manage Careers and Caregiving. Princeton University Press.

De Koning, Anouk. 2009. Global dreams: class, gender, and public space in cosmopolitan Cairo. American Univ in Cairo Press.

Frye, Margaret. 2012. Bright futures in Malawi's new dawn: Educational aspirations as assertions of identity. American Journal of Sociology, 117(6), pp.1565-1624. 
Frye, Margaret. 2017. "Cultural meanings and the aggregation of actions: the case of sex and schooling in Malawi.” American Sociological Review, 82(5), pp. 945-976.

Harding, David J. 2010. Living the drama: Community, conflict, and culture among inner-city boys. University of Chicago Press.

Harding, David J., Dobson, C.C., Wyse, J.J. and Morenoff, J.D. 2017. Narrative change, narrative stability, and structural constraint: The case of prisoner reentry narratives. American journal of cultural sociology, 5(1-2), pp.261-304.

Lamont, Michèle. 2012. Toward a comparative sociology of valuation and evaluation. Annual review of sociology, 38, pp.201-221.

Lamont, Michèle. 2019. "From 'Having' to 'Being:' Self-Worth and the Current Crisis of American Society." British Journal of Sociology, Forthcoming.

Lamont, Michèle, and Laurent Thévenot. 2000. Rethinking Comparative Cultural Sociology: Repertoires of Evaluation in France and the United States. Cambridge University Press.

Lamont, Michèle, Beljean, Stefan, and Clair, Matthew. 2014. What is missing? Cultural processes and causal pathways to inequality. Socio-Economic Review, 12(3), pp. 573608.

Lukose, Ritty. 2005. "Consuming globalization: Youth and gender in Kerala, India." journal of social history 38(4), pp. 915-935.

MacLeod, Jay. 2009. Ain't No Makin'It: Aspirations and Attainment in a Low-Income Neighborhood. Boulder, Colo.: Westview.

Merton, Robert K. 1938. Social structure and anomie. American sociological review, 3(5), pp.672-682. 
Mundy, Karen. 2006. "Education for All and the New Development Compact." Review of Education. 52, pp. 23-48.

O’Dougherty, Maureen. 2002. Consumption Intensified: The Politics of Middle-Class Daily Life in Brazil. Durham, NC and London: Duke University Press .

Omoeva, Carina. and Charles Gale. 2016. "Universal, but not free: Household schooling costs and equity effects of Uganda's Universal Secondary Education policy.” International Journal of Educational Development, 50, pp.41-50.

Polletta, Francesca, Pang Ching Bobby Chen, Beth Gharrity Gardner, and Alice Motes. 2011. "The sociology of storytelling." Annual review of sociology 37: 109-130.

Reynolds, John R. and Chardie L. Baird. 2010. "Is there a downside to shooting for the stars? Unrealized educational expectations and symptoms of depression.” American Sociological Review, 75(1), pp.151-172.

Reynolds Whyte, Susan, Michael A. Whyte, Lotte Meinert, and Jenipher Twebaze. 2013. “Therapeutic Citizenship: Belonging in Uganda's Projectified Landscape of AIDS Care." In Joao Biehl and Adriana Petryna, Eds, When People Come First: Critical Studies in Global Health. Princeton University Press.

Rosen, Eva. 2017. Horizontal Immobility: How Narratives of Neighborhood Violence Shape Housing Decisions. American Sociological Review, 82(2), 270-296.

Saguy, Abigail C. 2012. What's wrong with fat? Oxford University Press. 